\title{
Strategies and fundamental structures for FMS tool flow systems
}

\author{
S. C. Silva
}

Universidade do Minho,

Campus de Gualtar, 4710 - Braga, Portugal, phone: $+351+53$

60 4455, fax: +351+5360 4456, email scarmo@ci.uminho.pt

\begin{abstract}
A Tool Flow System, TFS, is an integral part of a wider system within a Flexible Manufacturing System, FMS: the Material Flow System. This also includes the Work Flow System.

Tool Flow Systems deal essentially with the storage, transport and handling of tools which are exchanged at the machine spindles. Work Flow Systems are particularly concerned with the storage, transport and handling of parts and auxiliary handling devices, such as fixtures and pallets.

This article focuses attention on the building blocks of TFS's and presents a classification, discussion of application and advantages of tool flow fundamental structures. It is argued that the configuration of TFS's and the level of tool replication, may greatly influence the performance and flexibility of production in FMS's.
\end{abstract}

\section{Keywords}

Flexible manufacturing systems, FMS, tool flow systems, multiple stage systems, MS, combined stage systems, CS and single stage systems, SS.

\section{INTRODUCTION}

Tool storage and flow in manufacturing systems, in general, and in Flexible Manufacturing Systems, FMS, in particular, requires careful planning. According to Stute (1974), in 1967 
Dolezalek used the term Flexible Manufacturing System to refer to a number of machines interlinked, through common control and transport systems, in such a way that automatic manufacture of different workpieces, requiring a variety of different operations, could be carried out. This definition still applies today as a general definition of a Flexible Manufacturing System, FMS.

When machines are very versatile they are able to perform a large range of operations during the manufacturing period conditioned, however, by those tools which a machine can access. If the access is restricted to a few tools, the machine might only be able to function as a special purpose machine. Therefore its versatility is not used completely during the manufacturing period with probable loss of efficiency.

To take advantage of FMS machine versatility, short term scheduling may be prepared offline. In this case a machine loading plan can be prepared for the manufacturing period, i.e. shift or day, where part processing sequence and part and tool assignment to machines can be established in advance of production. This assignment is known as the FMS loading problem (Stecke, 1981).

On the assumption that no machine breakdown happens, during the planned manufacturing period, then manufacturing according to the plan can be completely carried out by providing the machines with only the required tools. If big disturbances do occur during the planned manufacturing period then rescheduling the parts and tools is likely to be necessary. Small variances may be coped with by adequate on-line reloading control (Stute,1978).

\section{Tool variety reduction}

In FMS there is a predominance of multipurpose machines, i.e. machines which are capable.of performing a large number of different operations. This simplifies the control of tools and parts flow.

So, there is interest in establishing efficient tool flow systems with a coordinated tool supply to the different work stations. This is particularly relevant when tool variety and quantity can become large. In this case, usually, there are both economical and organisational advantages in reducing the number of tools in the system. This can be achieved on the one hand by adopting an off-line preparation of FMS loading plans based on the tools available, as referred to above, and on the other hand through a variety of standardisation and rationalisation measures directed at tool variety reduction (Hoop 1982, Zeleny 1982, Hankins 1984), figure 1.

\section{Tool availability}

One major aspect in the selection of the TFS configuration is the need to improve machine readiness as it is affected by tooling. Consequently, there is interest in separating, as much as possible, the tool set-up function from the machine cycle. To achieve this, new tool system configurations can be applied as it is discussed below. The best configuration to choose is influenced by the degree of automation in connection with the autonomous period desired for unattended manufacture and by other operational and organisational aspects as well as by economical reasons. 


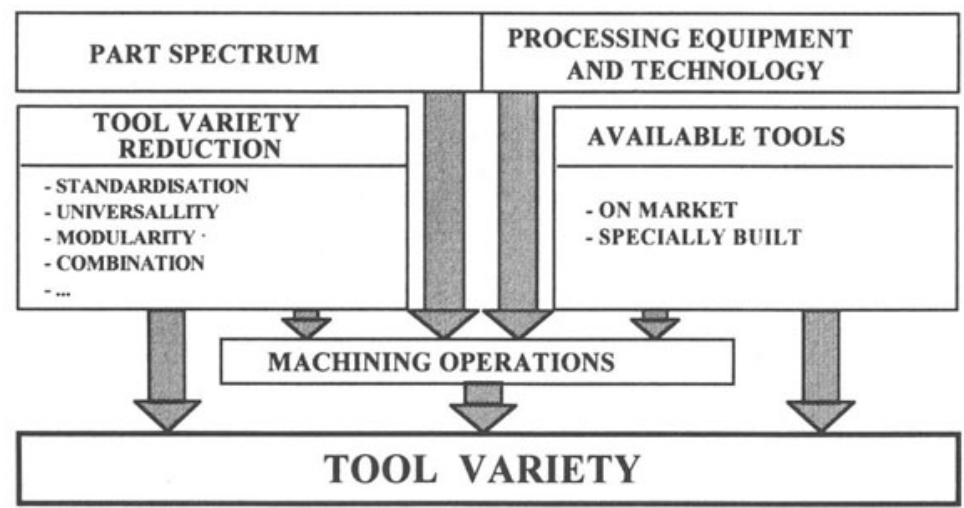

Figure 1 Intervening factors for tool variety determination.

\section{TOOL FLOW STRUCTURES}

A classification of fundamental tool flow structures for TFS's configuration design is presented in figure 4 . These structures can be developed from pertinent combinations of basic tooling systems elements as classified and shown in figures 2 and 3 . These elements include local and central tool stores, tool magazines, tool exchangers and tool and magazine transport and handling elements, namely vehicles, conveyors and automatic manipulators, such as industrial robots, widely used in TFS's of many FMS's.

Practical application of the classified tool flow structures were reported by Chmielnicki 1980, Hammer 1983, Binder 1983, Zeleny 1985, FMS Magazine 1985, Tomek 1986 and other authors.

When tools cannot be automatically accessed for tool change at the machine spindle, manual tool change has to be used, figure 4-case 1 . Such a solution allows some degree of flexible automation, since in FMS's machines are computer controlled, but unattended working is not possible.

By providing the machines with an automatic tool change system, performed from a local and/or central tool store, different degrees of unmanned work are possible.

\subsection{Tooling structures with central tool storage}

\section{Unattended work}

The solution of automatically accessing a central tool store permits a high degree of automation and, for large central stores, can allow long periods of unattended work. This solution can lead, also, to a good level of utilisation of tooling resources. This can be achieved through a continuous flow of tools from and into the tool magazines of the machines. This configuration is likely to require constant computerised supervision and control of the tool requirements, tool flow and tool life. 


\begin{tabular}{|c|c|c|c|c|c|}
\hline 0 & 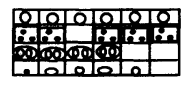 & $\begin{array}{l}\text { Static random or sequential } \\
\text { plan mtrix tool store }\end{array}$ & 6 & 目目目 $=$ & $\begin{array}{l}\text { Mobile random access } \\
\text { vertical stores }\end{array}$ \\
\hline 1 & & $\begin{array}{l}\text { Static random or sequential } \\
\text { cilindrical matrix tool store }\end{array}$ & 7 & 89: & $\begin{array}{l}\text { Plate/Drum axial tool } \\
\text { store }\end{array}$ \\
\hline 2 & & $\begin{array}{l}\text { Static line tool } \\
\text { store/stand }\end{array}$ & 8 & . & $\begin{array}{l}\text { Plate/Drum radial tool } \\
\text { store }\end{array}$ \\
\hline 3 & & $\begin{array}{l}\text { Radial chain } \\
\text { conveyor tool store }\end{array}$ & 9 & & Cone shaped tool magazine \\
\hline 4 & & $\begin{array}{l}\text { Axial chain conveyor } \\
\text { tool store }\end{array}$ & 10 & 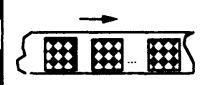 & $\begin{array}{l}\text { Conveyors for tool magazines } \\
\text { pallets or tool heads }\end{array}$ \\
\hline 5 & 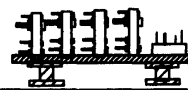 & $\begin{array}{l}\text { Stands for tool magazines/ } \\
\text { pallets or tool heads }\end{array}$ & 11 & & T H E R \\
\hline
\end{tabular}

Figure 2 Basic tool buffer and storage elements for FMS Tool Flow Systems.

\begin{tabular}{|c|c|c|c|c|}
\hline 0 & مים & $\begin{array}{l}\text { Automatic } \\
\text { Manipulators } \\
\text { Industrial Robots }\end{array}$ & 6 & Chain conveyors \\
\hline 1 & क्षक्व & $\begin{array}{l}\text { Overhead } \\
\text { Industrial Robots }\end{array}$ & 7 & $\begin{array}{l}\text { Rotating tool pallet } \\
\text { buffers }\end{array}$ \\
\hline 2 & प्रिण & $\begin{array}{l}\text { Floor } \\
\text { conveyors }\end{array}$ & 8 & Vehicles/carts/AGVs \\
\hline 3 & 包行 & $\begin{array}{l}\text { Overhead } \\
\text { conveyors }\end{array}$ & 9 & $\rightarrow\left[\begin{array}{ll}\text { Rotative tool magazines } \\
\text { / tool pallets or tool }\end{array}\right.$ \\
\hline 4 & 约 & $\begin{array}{l}\text { Cranes and } \\
\text { monorails }\end{array}$ & 10 & Man \\
\hline 5 & 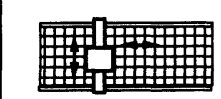 & $\begin{array}{l}\text { Stacker cranes or } \\
\text { stacker } \\
\text { manipulators }\end{array}$ & 11 & OTHER \\
\hline
\end{tabular}

Figure 3 Basic tool transport and handling elementsfor FMS Tool Flow Systems.

\section{Tooling reduction}

A further advantage of this system is that it may allow a reduction in the required number of identical tools in the manufacturing system. However, with centralised tool storage configurations, processing interference among machines may result when real-time machine 
loading and operations scheduling or sequencing is used. This is due to the fact that all machines are simultaneously sharing the same resources, in this case the same tool central store and, possibly, the same stored tools. Therefore, at some instants, it may happen that different machines are "fighting" for the same tools or at least simultaneously requiring the service of the tool exchange mechanism for tool change. This problem can be partially solved if off-line manufacturing loading plans are prepared in advance and tools are accordingly and adequately provided. This, may require some degree of tool duplication in the store.

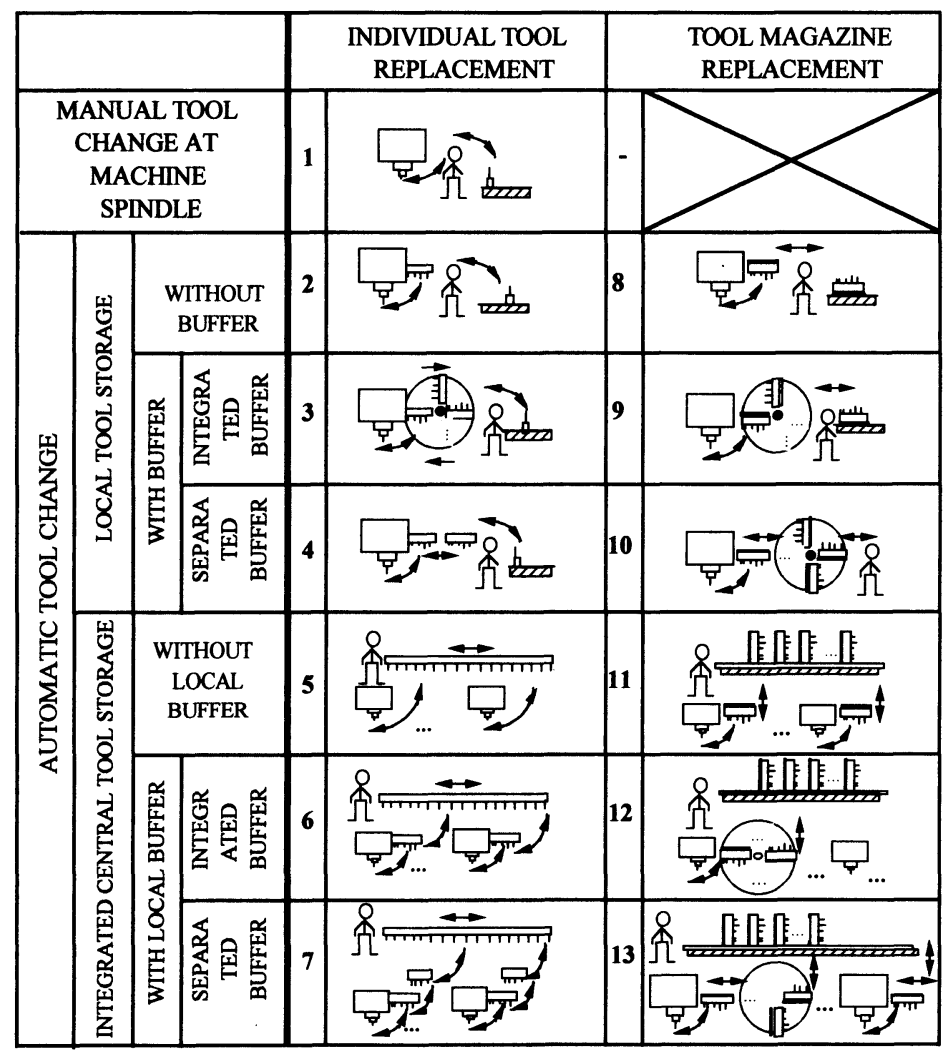

Figure 4 Tool flow strutuctures for FMS tool flow systems.

Although some action can be taken for avoiding simultaneous requirements of the same tools, through careful sequencing and part loading, in practice, applying this off-line loading strategy, may be unsatisfactory. This is due to the unpredictable behaviour of the tool requirements dynamics during part processing.

A disadvantage of the centralised tool storage configuration is the increased risk of complete system stoppage due to breakdown of the tooling system. To reduce this problem, machines can be designed and prepared to also work standing alone and tools manually changed while the tooling system recovers. 


\section{Minimum tooling and machining systems configuration}

Part routing flexibility advantages can be obtained applying centralised tool storage even under minimum tooling requirements, figure 5 .

The situation of minimum tooling requirements, in the extreme, is associated with the existence, within the system, at any time, of a single tool of each required type. This is theoretically enough for carrying out the processing of a chosen part mix, during a planned period of production as long as dynamic tool loading, (Silva, 1997), is allowed.

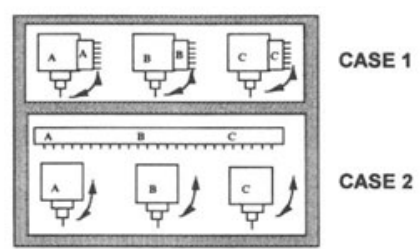

(a)

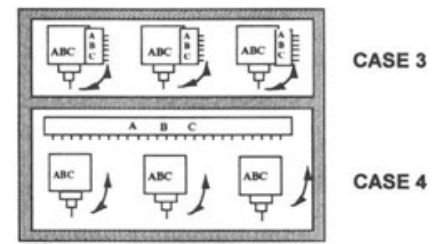

(b)

\begin{tabular}{|l|c|c|c|c|}
\hline CASE & CASE 1 & CASE 2 & CASE 3 & CASE 4 \\
\hline Number of Tools used & T & T & T & T \\
\hline Routing fexibility & None & None & None & Good \\
\hline
\end{tabular}

Legend:
(a) - Single purpose machines/Multi-stage Systems
(b) - Multiple purpose machines/Single Stage Systems
$\mathrm{T}$ - Minimum number of tools to process a part mix
Tool Store

Figure 5 The use of a central store for direct tool change into the spindle of the machines works best for single stage systems.

Although some flexibility advantages exist from using centralised tool storage in multiple stage systems, MS, it is in the combined stage systems, CS, and particularly in the single stage systems, SS, (Opitz, 1972), that full advantage can be taken from such a tool flow structure.

In MS systems part processing requires the use of a different machine type for carrying out each particular machining process. This, usually, requires a set of different tools. Unless duplication of machines of some type exists, part routing flexibility does not exist in these systems whatever the nature of the tool flow structure. In CS systems machines can carry out a few different processes. In SS systems it is considered that full part processing, of any loaded part, can be carried out in any of the machines in the system. In this case the full range of centrally stored tools are potentially available to all machines. Maximum routing flexibility can be achieved with this integrated concept, i.e. central tool storage and SS systems. These systems can be configured from very versatile identical machining centres.

For minimum tooling requirements, routing flexibility is not available, under local storage, whatever the type of system.

It should be stresses that, under minimum tooling and centralised tool storage approach, interference among working units may occur, for example, due to tooling and handling requirements. Therefore, this tool flow solution, in terms of reliability and flexibility, may not be a particularly good solution. Tool replacement can be enhanced to allow tools to be 
replaced during processing as a means to increase machine availability and, possibly, system performance.

\subsection{Individual tool replacement}

When tool magazines are an integral part of the machine, tool replacement at the machine is normally done on a tool by tool basis, figure 4, cases 1 to 7 .

In addition, or as an alternative, to a tool central store a replacement back-up tool buffer, at each machine, can also be provided. The tools in the buffer may be handled and accessed either manual or automatically. An operator or a handling device could be applied.

A few versions of the back-up tool buffer arrangement can be found in practice and three structures fitting this approach, under single tool replacement, are shown in figure 4, namely cases 3,4 , and 7 . They are designed to accommodate the tools needed for a large parts processing autonomy period and to reduce waiting time of the machines. Typically the tools in the tool magazine are replaced with the tools in the back-up store to cope with next parts processing requirements (Marsh 1981, FMS Magazine 1985). This buffering function is, in many cases, provided by the machine tool magazine itself, figure 4-case 6 . The tool buffer also functions as a means of extending the tool storage capacity near the machines.

\subsection{Exchanging magazines of tools}

The exchangeable magazine replacement approach, in opposition to the tool by tool replacement, can be associated with two basic arrangements as shown in figure 4:

A - Local tool exchangeable magazine store, cases 8 to 10.

B - Central tool exchangeable magazine store, cases 11 to 13

In the situation A the tool store is local with one or more magazines waiting to be replaced with the ones being used.

In the situation B the bulk of tool magazines or pallets with tools, destined for more than one machine, are located in a central tool magazine store. They are transferred to the machine areas through mechanised or automated transport and handling equipment. This concept integrates the local magazine storage cases.

By using the exchangeable magazines approach, in a manner which is similar to part pallets replacement at machines, many operational benefits can be explored. In particular, tool magazines can be associated with the processing requirements of the parts on a pallet or pallet group and routed together to the machines. When the flow of tool magazines is "linked" to that of part carriers or pallets the control of the flow of tools and parts is simplified and synchronised. In this case the same parts pallet carrier may also simultaneously carry the tool magazine for processing them.

When, as frequently it happens, the tool magazine or buffer represents an increased capacity of the local tool storage, longer periods of unmanned manufacture can be achieved.

Magazine replacement at a back-up tool buffer, performed during processing, together with an effective swapping magazines mechanism, in the processing area, tends to increase considerably the availability time of machines contributing, in this way, for improved performance of production.

The exchangeable magazine solution is likely to require considerable investment in tooling, tool magazines and handling equipment. To reduce this, not only tools but also tool 
magazines should be simple, standardised, universal, modular and flexible, Bullinger (1986), Hoop (1982), Zeleny (1982), Hankins (1984).

\section{LEVEL OF TOOL REPLICATION}

Although, as was referred above, flexibility of production may be achieved under minimum tooling, it is important to understand the impact of different levels of tool replication in system performance, under different TFS configurations.

The need for tool replication in FMS's, in a situation of tool sets replacement, has been studied by Silva (1988). The study does not centres on tool flow systems but solely, for a given tool flow system configuration, evaluates the influence of different levels of tool replication in CS and SS FMS system configurations. One of the main findings of this work is that, under adequate production control, only a very reduced level of tool replication is likely to be necessary for achieving very high levels of FMS performance. However, this work does not take into account the need for replication due to tool wear.

In a particular FMS case study Carrie, (1986) concluded that, the need for tool changes due to part variety was only a small part of the total number of changes and that tool wear can be highly influential of the need for tool changes.

The interrelationships and interdependence between tool flow structures and the level of tool replication and their articulation with other factors such as tool wear, part variety and operating strategies, seem to be so great that it is wise to study the full influence of tools replication and tool flow structures if good design and good operation of FMS's is to. be achieved.

\section{CONCLUSION}

The number of replicated tools and the configuration of Tool Flow Systems, TFS's, which integrate both the function of storage and that of movement and handling of tools, is critical to the efficiency of manufacturing systems and in particular to FMS's.

Many arrangements can be designed considering both the handling of tools either in sets or individually and the storage of tools centrally in the system and/or locally to machines.

It was shown that, in FMS's, the combination of machining system configurations with some TFS solutions, for the same number of tools, can be very restrictive to part routing flexibility while others can provide good flexibility for even minimum tooling.

The TFS solutions which can be generated by combining basic arrangements of tool flow structures for adequate level of tool replication, greatly influence the design of FMS's as well as the manner how FMS's must be run. Therefore for good design and operation of FMS thorough analyses of the influence of TFS configurations and levels of tool replication, for different operation strategies, must be conducted.

\section{REFERENCES}

Binder, R. and Hammer, H. (1983) Flexible Manufacturing Cell for Vertical 5 side Machining of Large Parts. WT-Zeitshrift für industrielle Fertigung, 73, No.4. 
Bullinger, H.-J., Warnecke, H.J.and Lentes, H.-P. (1986) Toward the Factory of the Future. International Journal of Production Research, 24, No. 4, 697-741.

Carrie, A. S. and Perera, D. T. S. (1986) Work Scheduling in FMS under Tool Availability. Constraints. International Journal of Production Research, 24, No.6, 1299-1308.

Chmielnicki, S. and Stute G. (1980) Simulation - ein Hilfsnittel bei der Auslegung des Werkzeugflusses in Flexiblen Fertigungssystemen. Industrie Anzeiger, 102,. No. 20, 28-9.

FMS Magazine, (1985) British Aerospace Aims Sky High. FMS Magazine, April.

Hammer, H. (1983) Verbesserung der Wirtshaftlichkeit durch flexible Automatisierung beim Bohren unf Fräsen. ZwF-Zeitschrift, 78, No.2, 77-96.

Hankins, S.L. and Rovito, V.P.(1984) The Impact of Tooling in Flexible Manufacturing Systems. 2nd. Biennial Int. Machine Tool Technical Conf., National Machine Tool Builders' Association.

Hoop, P. (1982) Einsatz von kombinationswerkzeugen in FFS. Zeitschrift für Metalbearbeitung, 76, No 7.

Marsh, P. (1981) Britain advances in computerized factories. New Scientist, 89, No.1245.

Opitz, H. and Hormann, D.(1972) Planning and Utilization of FMS. Annals of the CIRP 21/1/72, 29- 30.

Silva, S. C. (1988) An Investigation into tooling requirements and strategies for FMS operation. PhD Thesis, Loughborough University of Technology, U.K..

Silva, S.C. (1997) Analytical assessment of tooling requirements for FMS design and operation. Submited to the OE/IFIP/IEEE International Conference on Integrated ans Sustainable Industrial Production, ISIP'97

Stecke, K. and Solberg, J.J.( 1981) Loading and Control Policies for FMS. International Journal of Production Research, 19, No.5, 481-90.

Stute, G., (1974) Flexible Fertigungssysteme. WT-Zeitshrift für industrielle Fertigung, 64 No.3.

Stute, G. (1978) Organizational Control in an FMS FMS Workshop conference, Milwaukee, USA.

Tomek, P. (1986) Tooling Concepts for FMS, Proc. of the 5th Int.Conf. on FMS.

Zeleny, J.( 1985) Unmanned Technology and Control Strategies in Flexible Manufacturing Systems with Random Flow of Parts and Tools, Annals of the CIRP Vol. 34/1/1985

Zeleny, J. (1982) Manufacturing Cells with Automatic Tool Flow for Unmanned Machining of Box-like Workpieces Manufacturing Systems, Vol.11 No.4.

\section{BIOGRAPHY}

Dr. S. Carmo Silva is a member of the Departamento de Produção e Sistemas at the Universidade do Minho, in Braga, Portugal. At present Dr. Carmo Silva is the head of the Industrial Management and Systems group. He got his $\mathrm{PhD}$, in 1988, from Loughborough University and his MSc degree from UWIST in U.K, both in the area of Production Systems and Management. He is also graduated in Mechanical Engineering by Oporto University, Portugal. His main academic and research intestests fall into the general concept of Manufacturing Systems Engineering and, in particular into the area of design and operation of integrated manufacturing and assembly systems. 